3. Kawai T, Akira S. Toll-like receptors and their crosstalk with other innate receptors in infection and immunity. Immunity 2011;34:637-650.

4. Shultz LD, Brehm MA, Garcia-Martinez JV, Greiner DL. Humanized mice for immune system investigation: progress, promise and challenges. Nat Rev Immunol 2012;12:786-798.

Copyright $\odot 2013$ by the American Thoracic Society

\section{Obesity Paradox?}

To the Editor:

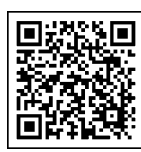

The obesity paradox is a phrase often used to describe the curious epidemiological finding that obese individuals are somehow predisposed to the development of disease, but outcomes once the disease is established are improved when compared with lean counterparts. The obesity paradox has been described in association with various cardiovascular conditions, but recently, a similar phenomenon was reported in patients with acute lung injury (1-3). However, because of the complexity of reading chest radiographs from obese individuals (e.g., because of atelectasis, increased soft-tissue density, and low lung volumes) many experts believe that "predisposition" as well as "improved outcomes" may be explained, at least in part, by the fact that acute lung injury is overdiagnosed in obese individuals. It is for this reason I was disappointed to find out that body mass index was not included in the excellent study by Thille and colleagues published in the Journal (4). If the authors collected data on height and weight, could they kindly evaluate whether an inverse association between obesity and diffuse alveolar damage pathology was observed in their study?

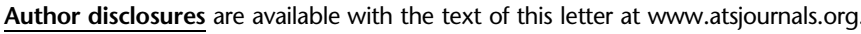

Ross S. Summer, M.D.

Thomas Jefferson University

Philadelphia, Pennsylvania

\section{References}

1. Gong MN, Bajwa EK, Thompson BT, Christiani DC. Body mass index is associated with the development of acute respiratory distress syndrome. Thorax 2010;65:44-50.

2. Morris AE, Stapleton RD, Rubenfeld GD, Hudson LD, Caldwell E, Steinberg KP. The association between body mass index and clinical outcomes in acute lung injury. Chest 2007;131:342-348.

3. O'Brien JM Jr, Welsh CH, Fish RH, Ancukiewicz M, Kramer AM; National Heart, Lung, and Blood Institute Acute Respiratory Distress Syndrome Network. Excess body weight is not independently associated with outcome in mechanically ventilated patients with acute lung injury. Ann Intern Med 2004;140:338-345.

4. Thille AW, Esteban A, Fernández-Segoviano P, Rodriguez J, Aramburu J, Peñuelas O, Cortés-Puch I, Cardinal-Fernández P, Lorente JA, FrutosVivar F. Comparison of the Berlin definition for acute respiratory distress syndrome with autopsy. Am J Respir Crit Care Med 2013;187:761-767.

Copyright $\odot 2013$ by the American Thoracic Society

\section{The Dynamics of Polymicrobial Biofilms}

To the Editor:

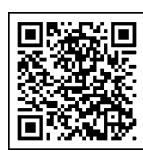

In their study of the respiratory microbiome, Morris and colleagues explored the microbiology of the lower respiratory tract in relation to the oral microbiome (1). Although microbial inhabitants in lung parenchyma did not appear to be entirely derived from direct translocation from microbial communities in the mouth as discussed, the influence and dynamics of microbial biofilms within the oral cavity, and subsequently through to the lower respiratory tract, were not discussed.

The use of molecular techniques for microbial profiling has allowed the exploration of previously uncultivable organisms, which ultimately allows observation of patterns and similarities between communities of bacteria (2). Although microbiologists typically work with bacteria in planktonic culture, in biological systems, most bacteria exist in biofilms, which are complex polymicrobial networks embedded in extracellular polymeric substances to structurally enhance the biofilm (3). A biofilm is highly dynamic in terms of both behavior and microbial content, and as typified by dental plaque in the oral cavity, can play a key role in disease. Indeed, plaque-mediated infections such as dental caries and periodontal diseases actually occur when there is a "microbial shift" in the microbial community of the biofilm associated with local environment changes. Given disease associations and ease of access, oral biofilms have been extensively studied compared with those from other body sites; age, diet, smoking, health status, host defenses, $\mathrm{pH}$, and the location of the biofilm itself can all contribute to biofilm modifications and adaptations. Gene expression and quorumsensing mechanisms within biofilms also support their ability to frequently adapt to differing conditions and alter their virulence (4).

Although there is anatomical contiguity between the oral cavity and the distal air spaces of the lung, the species identified along the tract may not result from simple kinetics alone. Indeed, given our understanding of the dynamics of plaque biofilms, it would be surprising to observe the same distribution of bacteria in environments that differ substantially with respect to gas flow, nutrients, redox potential, and host defense molecules - even if starting with identical polymicrobial communities. In this context, the observation by Morris and colleagues that the pulmonary microbiome of healthy individuals resembles that of the oral cavity, but that the relative representation of bacterial species differs, might indeed be expected. Nevertheless, by characterizing the lung microbiome in a large cohort of healthy individuals, this study will prove invaluable for the further study of the pulmonary microbiome in respiratory diseases.

Author disclosures are available with the text of this letter at www.atsjournals.org.

$$
\begin{aligned}
& \text { Kirsty Sands, B.Sc. } \\
& \text { David W. Williams, Ph.D. } \\
& \text { Melanie Wilson, Ph.D. } \\
& \text { Michael Lewis, Ph.D., B.D.S. } \\
& \text { Cardiff University } \\
& \text { Cardiff, United Kingdom } \\
& \text { Matthew P. Wise, D.PhIL. } \\
& \text { University Hospital of Wales } \\
& \text { Cardiff, United Kingdom }
\end{aligned}
$$

\section{References}

1. Morris A, Beck JM, Schloss PD, Campbell TB, Crothers K, Curtis JL, Flores SC, Fontenot AP, Ghedin E, Huang L, et al.; Lung HIV Microbiome Project. Comparison of the respiratory microbiome in healthy nonsmokers and smokers. Am J Respir Crit Care Med 2013;187: 1067-1075.

2. Dewhirst FE, Chen T, Izard J, Paster BJ, Tanner ACR, Yu W-H, Lakshmanan A, Wade WG. The human oral microbiome. J Bacteriol 2010;192:5002-5017.

3. Avila M, Ojcius DM, Yilmaz O. The oral microbiota: living with a permanent guest. DNA Cell Biol 2009;28:405-411.

4. Sifri CD. Healthcare epidemiology: quorum sensing: bacteria talk sense. Clin Infect Dis 2008;47:1070-1076.

Copyright $\odot 2013$ by the American Thoracic Society 